\title{
Defining Treatment Response, Remission, Relapse, and Recovery in First-Episode Psychosis: A Survey among Korean Experts
}

\author{
Bong Ju Lee', Sung-Wan Kim², Jung Jin $\mathrm{Kim}^{3}$, Je-Chun $\mathrm{Yu}^{4}$, Kyu Young Lee ${ }^{5}$, \\ Seung-Hee Won ${ }^{6}$, Seung-Hwan Lee ${ }^{7}$, Seung-Hyun Kim ${ }^{8}$, Shi Hyun Kang ${ }^{9}$, \\ Euitae Kim ${ }^{10}$, Kunhyung Kim ${ }^{11}$, Yang Hong Piao ${ }^{12,13}$, and Young-Chul Chung ${ }^{12,13 \bowtie}$ \\ 'Department of Psychiatry, Inje University Haeundae Paik Hospital, Inje University College of Medicine, Busan, Republic of Korea \\ 2Department of Psychiatry, Chonnam National University Medical School, Gwangju, Republic of Korea \\ ${ }^{3}$ Department of Psychiatry, The Catholic University of Korea, Seoul St. Mary's Hospital, Seoul, Republic of Korea \\ ${ }^{4}$ Department of Psychiatry, Eulji University School of Medicine, Eulji University Hospital, Daejeon, Republic of Korea \\ ${ }^{5}$ Department of Psychiatry, Eulji University School of Medicine, Eulji General Hospital, Seoul, Republic of Korea \\ ${ }^{6}$ Department of Psychiatry, Kyungpook National University School of Medicine, Daegu, Republic of Korea \\ ${ }^{7}$ Department of Psychiatry, Inje University College of Medicine, Goyang, Republic of Korea \\ ${ }^{8}$ Department of Psychiatry, Korea University College of Medicine, Guro Hospital, Seoul, Republic of Korea \\ ${ }^{9}$ Department of Psychiatry, Seoul National Hospital, Seoul, Republic of Korea \\ ${ }^{10}$ Department of Neuropsychiatry, Seoul National University Bundang Hospital, Seongnam, Republic of Korea \\ ${ }^{11}$ Department of Occupational and Environmental Medicine, Institute of Environmental and Occupational Medicine, Busan Paik Hospital, \\ Inje University, Busan, Republic of Korea \\ ${ }^{12}$ Department of Psychiatry, Chonbuk National University Medical School, Jeonju, Republic of Korea \\ ${ }^{13}$ Research Institute of Clinical Medicine of Chonbuk National University-Biomedical Research Institute of Chonbuk National University Hospital, \\ Jeonju, Republic of Korea
}

Objective For the proper treatment of first-episode psychosis, assessment of treatment response, remission, relapse, and recovery is important. Therefore, the present study aimed to develop operational definitions of clinical outcomes in first-episode psychosis.

Methods A questionnaire was developed by a panel of experts and underwent three revisions. The final survey was presented to 150 psychiatrists who were members of the Korean Society for Schizophrenia Research. Respondents selected factors that they believed were important to consider while defining treatment response, remission, relapse, and recovery using a 6-point Likert scale. Selected factors that constituted each definition were statistically extracted, and operational definitions were developed.

Results A total of 91 experts responded to the survey. The extent of reduction in psychopathology, socio-occupational functioning, and duration of each state were the core factors of each definition. Outcomes obtained from discussions and consultations by experts have been summarized and proposed.

Conclusion The criteria developed in this survey tended to be somewhat stricter than those used by other studies. The fundamental reason for this is that this survey focused on first-episode psychosis. A better understanding of each definition in first-episode psychosis is necessary to improve effective treatment outcomes.

Psychiatry Investig 2020;17(2):163-174

Key Words First-episode psychosis, Treatment response, Remission, Relapse, Recovery, Definition.

\section{INTRODUCTION}

The goals in treating first-episode psychosis (FEP) include

Received: September 12, 2019 Revised: November 17, 2019

Accepted: December 2, 2019

$\triangle$ Correspondence: Young-Chul Chung, MD, PhD

Department of Psychiatry, Chonbuk National University Medical School, 20 Geonji-ro, Deokjin-gu, Jeonju 54907, Republic of Korea

Tel: +82-63-250-2185, Fax: +82-63-275-3157, E-mail: chungyc@jbnu.ac.kr

(a) This is an Open Access article distributed under the terms of the Creative Commons Attribution Non-Commercial License (https://creativecommons.org/licenses/bync/4.0) which permits unrestricted non-commercial use, distribution, and reproduction in any medium, provided the original work is properly cited. targeting symptoms, preventing relapse, and increasing adaptive functioning so that the patient can be integrated back into the community as a normally functioning individual. ${ }^{1}$ It is important to accurately determine the state of the patient during treatment in order to formulate future treatment strategies. ${ }^{2}$ Although several studies have attempted to derive definitions of the numerous treatment outcomes, objective and clear definitions of treatment response, remission, relapse, and recovery in the treatment of FEP have yet to be established. ${ }^{3-5}$ This ambiguity hampers comparisons between study results and has 
a negative impact on future treatment planning.

In general, researchers use rating scales such as the Positive and Negative Syndrome Scale (PANSS), ${ }^{6}$ Brief Psychiatric Rating Scale, ${ }^{7}$ Scale for the Assessment of Negative Symptoms (SANS), ${ }^{8}$ and Clinical Global Impression (CGI) scale ${ }^{9}$ to judge treatment response, and the criteria for determining the treatment response vary from $20 \%$ to $50 \%$ of reduction. ${ }^{10,11}$ Moreover, the period after treatment to evaluate the treatment response is another issue that should be considered. It may be meaningful to only consider the period of active treatment to avoid unnecessary delay; however, the full therapeutic effect may not manifest during this time. ${ }^{12-16}$ If the patient responds to treatment, the patient should be reminded that symptomatic improvement lasts for a certain period of time but during remission, a patient may still have symptoms, irrespective of the magnitude of improvement. ${ }^{17}$ The definition of remission also varies. ${ }^{18-22}$ There has been increased focus on treatment outcome for schizophrenia; the Remission in Schizophrenia Working Group (RSWG) developed a consensus definition of symptomatic remission in schizophrenia. ${ }^{23}$ This innovative approach for standardizing the definition of outcome in schizophrenia could facilitate research and support a positive, longer-term approach of studying the outcome in patients with schizophrenia. ${ }^{4}$ Although symptomatic improvement is maintained after treatment, worsening of psychotic symptoms could be observed in clinical practice. It is important to determine whether it constitutes a relapse to plan the next appropriate treatment step for the patient. When defined as relapse, the patient's symptoms may be considered on the premise that they have improved over a period. Therefore, relapse should be evaluated qualitatively and quantitatively. The core characteristics of relapse are identified as follows: the reappearance of schizophrenia symptoms in patients who have been symptom-free after an initial episode (there is need to consider a minimum period of time for reappearance of schizophrenia symptoms), worsening of clinical status severity, worsening of functioning, and reappearance of positive symptoms. ${ }^{5}$ Recovery, the ultimate goal of treatment, should include functional recovery as well as symptomatic improvement. Recovery is defined as adequate function and not impeded social and occupational function social and occupational function, but no clear consensus on the definition of recovery exists either. ${ }^{24}$

This lack of uniformity in the definitions of clinical outcomes has had an impact on the clinical guidelines that seek to distill evidence from various studies. Not surprisingly, given the variation used in the criteria among studies, treatment guidelines use vague definitions that are open to a wide range of interpretations, potentially leading to inconsistent clinical management and treatment delays. Complicating this, inconsistent results have been reported with the application of the same definition.
For example, the reported rates of remission in FEP range between $17 \%$ and $78 \% .{ }^{4,25}$ Furthermore, the rate of recovery ranges from $13.5 \%$ to $42 \%$. ${ }^{4}$ These inconsistencies can confuse clinicians in the field and make it impossible to comprehensively compare results among studies. ${ }^{26}$ In view of this, the Committee of Treatment Guidelines for First-Episode Psychosis in Korea was formed to establish consensus criteria to standardize the definition of treatment response, remission, relapse, and recovery. By comparing the status of individuals with FEP on the basis of each definition, it would be possible to determine which treatment is more effective, such that it can be used for more efficient evaluation in clinical practice and new research. The aim of the study, therefore, was to develop criteria to aid in clinical trials and clinical practice.

\section{METHODS}

\section{Literature review}

An intensive approach was adopted to develop criteria for the definitions of treatment response, remission, relapse, and recovery in FEP. First, we performed a literature review of these definitions. We searched articles and abstracts using the following keywords: first-episode psychosis, treatment response, remission, relapse, recovery, and outcome in PubMed from January 1980 to January 2016. We included studies that involved patients with first-episode schizophrenia spectrum psychotic disorder, namely schizophrenia, schizophreniform disorder, nonaffective psychosis, delusional disorder, and psychotic disorder not otherwise specified. Titles and abstracts were reviewed to initially determine eligibility. The reference lists of relevant original research and review articles were also searched to further identify potential studies. We conducted a systematic review to judge which factors were appropriate for each definition. A total of 93 studies were identified, of which 66 met the selection criteria and were used to develop a questionnaire. Operationalized criteria of treatment response, $3,18,19,27-44$ remission, ${ }^{3,18-23,27,41,42,44-58}$ relapse, ${ }^{19,21,22,27,34,39,48,53,55,57,59-73}$ and recovery $^{3,30,58,74-82}$ were reported in $22,29,26$, and 14 studies, respectively.

\section{Survey}

This study was approved by the Medical Research Ethics Committee and Institutional Review Board of the Inje University Haeundae Paik Hospital (2016-06-019).

First, we recorded whether the criteria from the literature review were operationalized. Next, the key factors that constituted each definition were finely extracted. Subsequently, a committee composed of 10 expert members of the treatment guideline committee for first-episode psychosis of the Korean Society for Schizophrenia Research (KSSR) was established. 
The committee met four times in 2016 and mapped out the key criteria for each definition and operationalized them. Following this, the committee developed a survey, which was defined and modified three times. In its final version, it was composed of four parts with a total of 48 items, including four items for demographic data. Respondents were asked how strongly they agreed or disagreed with each statement on a 6-point Likert scale (strongly agree: 5 to strongly disagree: 0 ). In addition, respondents were asked to rank their preferences regarding various operational criteria. A brief introduction of the meaning and methods was provided to the respondents. Subjects were instructed to respond to questions for individuals with FEP and were informed that several commonly used instruments were included as part of the survey items. Finally, respondents were instructed that each item itself was not a definition but factors constituting a definition and which specific factors have been used by the researchers.

We recruited all KSSR members to take part in the survey to identify the key areas of agreement and disagreement. The survey was conducted via mail. One hundred and fifty members were invited via telephone and asked to participate in the survey. During the 30-day collection period, 91 responses (60.7\%), covering all areas of South Korea, were received. Ten members of the KSSR refused to respond. Responses were synthesized and refined during subsequent discussions among the committee to derive a consensus recommendation. Following this, the committee met to consider and revise the criteria for which there was a lack of consensus. The revised criteria were circulated to all KSSR members and presented as part of an open workshop at a special interest meeting for further discussion, input, and refinement. Finally, consensus was reached regarding this publication through review by all authors. The results of the survey were presented and discussed at the UK-Asian Symposium on Biomarkers of Psychosis (2016) and the 2016 KSSR autumn meeting.

\section{Measurements}

PANSS is an internationally validated assessment tool based on 30 items that measure positive and negative psychotic symptoms and general psychopathology symptoms. Each item is rated based on seven categories of severity, resulting in a total score that ranges from 30 to $210 .^{6}$ The SANS measures negative symptoms on a 25 item, 6-point scale. Items are listed under the five domains of affective blunting, alogia, avolition/apathy, anhedonia/asociality, and attention. ${ }^{8}$ The CGI scale is an overall clinician-determined summary measure that takes into account all available information and comprises two companion one-item measures evaluating the following: (a) severity of psychopathology from a scale from 1 to 7 and (b) change from the initiation of treatment on a similar seven-point scale. Sub- sequent to a clinical evaluation, the CGI scale can be completed in less than a minute by an experienced rater. ${ }^{9}$

\section{Statistical analysis}

Most of the survey consisted of assessing specific items using a 6-point (0-5) Likert scale. We scored the answers to these questions as follows: if the response was $>3$ points (neutral), it was determined that the item was appropriate. Responses were summarized by frequency and percentage and mean \pm standard deviation. Differences were tested using Fisher's exact test for categorical data and the Mann-Whitney's U test or KruskalWallis test for numeric data. For ranked preferences, the percentage of the first ranked item was calculated. In addition, a weighted-average ranking was calculated for each answer to evaluate the most preferred answer. Statistical analysis was performed using IBM SPSS Statistics version 21.0 (IBM Corp., Armonk, NY, USA). $\mathrm{p}<0.05$ was considered statistically significant. This study was exploratory by nature, and therefore no adjustment for multiple testing was applied.

\section{RESULTS}

A total of 91 experts (60.7\%) participated in the survey. The mean (standard deviation ${ }^{71}$ ) age of the experts and duration of practice in psychiatry were 47.3 (9.2) and 19.6 (9.3) years, respectively. The percentage of male respondents was $79.1 \%$. The classification of experts according to their job type was as follows: $44(48.4 \%)$ worked at a training hospital with a psychiatry residency program; 24 (26.4\%) worked at psychiatric hospital, $10(11 \%)$ at a private clinic, eight $(8.8 \%)$ at a general hospital, and five $(5.5 \%)$ at another facility.

Table 1 shows the results of the consensus for defining treatment response, remission, relapse, and recovery. All results of the survey are summarized in the Supplementary Table 1-9 (in the online-only Data Supplement).

\section{Treatment response}

Instead of positive symptoms alone, simultaneously evaluating both positive and negative symptoms to judge the treatment response showed a statistically high level of consensus $(\mathrm{p}<0.001)$. For the PANSS total score, "30\% or $50 \%$ reduction" was statistically higher than " $20 \%$ reduction" ( $<<0.001)$. In the case of positive symptoms, the most appropriate criteria were surveyed, and most respondents held that all seven PANSS positive items should be evaluated. On the CGI-Improvement (CGI-I), there was no statistically significant difference between the options "improved to $\geq 2$ points when the baseline CGI-Severity (CGI-S) score was $\geq 4$ (moderate), and improved to $\geq 1$ point when the baseline CGI-S score was 3" and "improved to $\geq 2$ points" ( $p=0.453$ ). When asked regarding the appropriate 
Table 1. Definition of treatment response, remission, relapse, and recovery

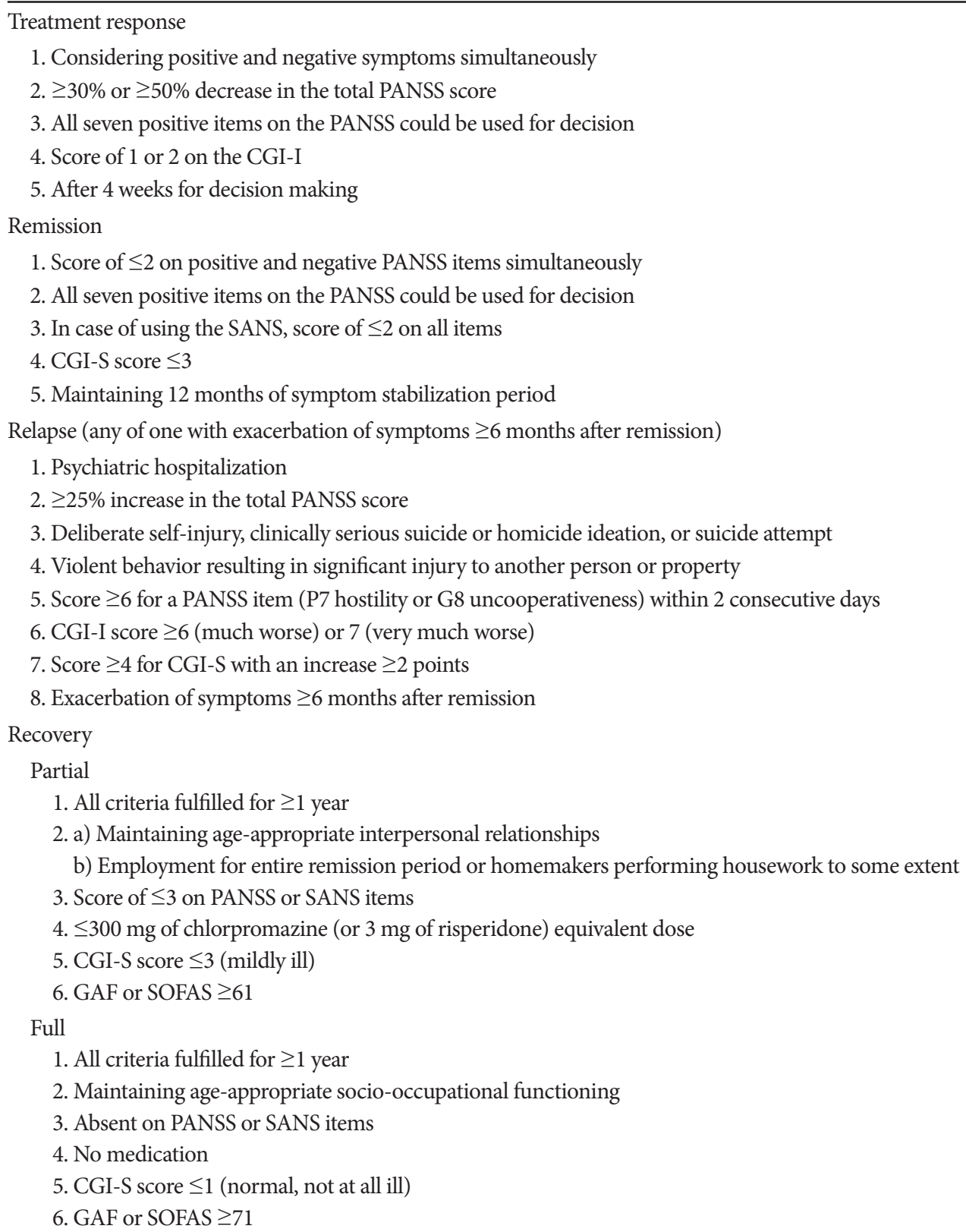

CGI-S: Clinical Global Impression-Severity, CGI-I: Clinical Global Impression of Improvement, PANSS: Positive and Negative Syndrome Scale, SANS: Scale for the Assessment of Negative Symptoms, GAF: Global Assessment of Functioning, SOFAS: Social and Occupational Functioning Assessment Scale

time to decide on a treatment response after initiation of medication, $53.3 \%$ of the respondents selected 4 , followed by $6(21.1 \%)$ and then $2(15.6 \%)$ weeks.

\section{Remission}

The mean $\pm S D$ of the consensus on the inclusion of social and occupational function to the criteria of remission was $4.08 \pm$ 1.05. Most respondents answered " $\leq 2$ (minimal) than $\leq 3$ (mild)" to judge the severity of each PANSS item score for the remis- sion criteria $(\mathrm{p}<0.001)$. For positive symptoms, the most appropriate criteria were surveyed and most respondents agreed that all seven PANSS positive items should be used. The use of the SANS for the evaluation of negative symptoms showed a level of agreement of approximately $3.66 \pm 1.05$, and when the SANS (76) was used, the criterion of severity was " $\leq 2$ (minimal) than $\leq 3$ (mild)" to judge the severity of each SANS item score $(\mathrm{p}<0.001)$. The agreement level for using a CGI-S score of 3 or lower was $3.66 \pm 0.79$ for symptom improvement. The 
most frequent response regarding the maintenance period of the remission state was 12 months (56\%), followed by $6(33.0 \%)$ and $3(6.6 \%)$ months.

\section{Relapse}

The degree of consent on defining relapse based on the patient being admitted to the hospital due to aggravation of psychiatric symptoms was very high $(4.53 \pm 0.81)$. The agreement on an increase of $25 \% \geq$ PANSS total score showed statistically significance than the "increase of more than 20\%" ( $p=0.001)$. The degree of agreement on the clinically significant suicidal attempt or suicide was $4.20 \pm 1.02$ and on intentional self-injury behavior, $4.00 \pm 0.97$. In the case of 2 or more consecutive days, on the Hostility or Uncooperation PANSS items, the level of consent was significantly higher for " 6 points or higher" than for " 5 points" ( $p=0.005)$. Moreover, the degree of consent was $4.60 \pm 0.61$ when the CGI-I was 6 or $7,4.00 \pm 0.72$ when the CGI$S$ was 4 or higher, but $3.06 \pm 0.99$ for higher levels of psychiatric treatment (increasing number of visits to the clinic) and $3.07 \pm 1.04$ when there was increase of $\geq 25 \%$ in maintained medication dose.

In addition, when relapse was defined using the PANSS, $44.3 \%$ of the respondents selected " 4 points $\geq$ any of the four PANSS positive items ( $\mathrm{P} 1, \mathrm{P} 2, \mathrm{P} 3, \mathrm{P} 6)$ with increase $\geq 2$ points" as their first priority. The respondents reported that the duration of the stable condition prior to relapse should be at least $6(59.3 \%)$ or $12(28.6 \%)$ months.

\section{Recovery}

The degree of consent on dividing recovery into partial and full was $3.94 \pm 1.22$ and $3.37 \pm 0.99$, respectively, for a PANSS total score $\leq 36$ points.

For the criteria of social functioning, "having age-appropriate interpersonal relationships" (46.0\%), followed by "meeting with an acquaintance more than twice a month or making phone calls" (40.2\%) were selected as the definition for partial recovery. However, for full recovery, most respondents selected "having age-appropriate interpersonal relationships" (85.7\%). The difference between the two definitions was statistically significant $(\mathrm{p}<0.001)$. For the criteria of occupational functioning, "when working or preparing for work or when the students went to school somewhat regularly and homemakers performed some housework" was highly selected at $46.5 \%$ for partial recovery and for full recovery, "having appropriate occupational or academic function and homemakers performing appropriate housework" was selected (68.5\%). This difference was also statistically significant $(\mathrm{p}<0.001)$. The response to the question regarding the cutoff value for the general function assessment of full remission with the Global Assessment of Functioning $(\mathrm{GAF})^{83}$ and Social and Occupational Functioning Assess- ment Scale (SOFAS) $)^{84}$ was (mean \pm SD) $76.86 \pm 7.38$ and $77.23 \pm$ 7.44 , respectively. The cutoff value for partial recovery was $64.51 \pm 7.88$ and $64.96 \pm 8.48$ for the GAF and SOFAS, respectively. According to the criteria of psychiatric symptoms (using the PANSS), $77.6 \%$ of the respondents selected " 3 points or lower" for partial recovery and $86.3 \%$ selected "absent" for full recovery $(\mathrm{p}<0.001)$. For the SANS criteria, the same pattern was revealed at $69.0 \%$ for " 3 points or lower" and $72.3 \%$ for "absent" for partial and full recovery, respectively $(\mathrm{p}<0.001)$. For the criteria of the CGI-S, "3 points or lower" and "absent" were most preferred for partial and full recovery, respectively $(\mathrm{p}<0.001)$. In terms of antipsychotic dosage, "300 mg or lower of chlorpromazine equivalent” (48.8\%) and "absent” (60.5\%) were selected for the definition of partial and full recovery, respectively ( $\mathrm{p}<0.001)$. Finally, $44.3 \%$ and $21.6 \%$ of the respondents answered that the period for maintenance of the recovery state should be 1 year and 2 years for partial and full recovery, respectively.

\section{DISCUSSION}

Every decision in clinical practice and clinical trials for the treatment of FEP should consider the outcomes. Because there is no clear definition of clinical outcomes in FEP, we sought to determine them and describe the subjective opinions of experts as objectively as possible.

Our results showed that besides our generally moderate rigor of development, the results of this survey might be difficult to apply simply and had a low legitimization base for clear use in clinical practice and research. The respondents' opinions regarding factors that could be used to build definitions showed that, in practice, it may be challenging to develop operational definitions. However, the originality of our study lies in determining factors that could construct each definition based on literature review and the interpretation of responses from a nationwide survey of key representatives in Korea.

\section{Treatment response}

Treatment response denotes the extent to which a patient improves, irrespectively of the presence or absence of symptoms. ${ }^{17}$ Most respondents reported that positive and negative symptoms should be evaluated at the same time when determining the treatment response. Although an important factor in determining treatment response is the change in positive symptoms from baseline, many researchers and clinicians use the change in the PANSS total score from baseline. Most studies on treatment response confirm the degree of change in symptoms from baseline or observe changes in relative status. In case of using percentage of reduction on rating scale, some individuals showing treatment response would still be con- 
sidered markedly ill. ${ }^{3}$ Additionally, when researchers calculate percentage reduction on the PANSS scores from baseline, they must remember to first subtract the minimum scores of $30 .^{2}$ To overcome these problems, Leucht ${ }^{3}$ proposed instead the use of the CGI scale. The inclusion of positive and negative symptoms for considering the treatment response does not differ from the results of previous studies because the PANSS total score also includes these two symptoms. ${ }^{17}$ There seems to be no consensus on whether $30 \%$ or $50 \%$ reduction on the PANSS total score should be used to define treatment response. ${ }^{3,17} \mathrm{Al}$ though a widely held belief is that low response cutoffs are more sensitive for detecting differences between drugs and placebo than are higher cutoffs, ${ }^{2}$ others have contested that selecting the most sensitive cutoff is not recommended because clinically meaningful cutoffs are important for clinical trials to be informative for practice. ${ }^{3}$

According to one meta-analysis of PANSS factor structure, P2, Conceptual Disorganization, and P4, Excitement, are not included in the positive symptoms of schizophrenia. ${ }^{85}$ In the acute state of schizophrenia, excitement and disorganization symptoms can be seen and improved by appropriate treatment. Meanwhile, over $40 \%$ of the respondents in this study selected all seven positive symptoms as appropriate for the assessment of positive symptoms. Instead of evaluating the treatment response based on change in total score, summing the score of the items may have additional explanatory power. However, evaluating a limited number of items will be advantageous in terms of length of assessment, whereas evaluating all items requires more time and effort. Approximately half the respondents $(53.3 \%)$ considered 4 weeks as the best time to determine the treatment response. Treatment guidelines for patients with schizophrenia have typically suggested a requirement for a 4-8-week antipsychotic response time. ${ }^{12}$ The lack of response to antipsychotics in weeks $1-2$ when treating acutely ill patients with schizophrenia has been shown to predict a poor response with short-term trial endpoints. ${ }^{12-14}$ However, other studies have suggested that limited early symptom improvement is not an identifier of first-episode patients who will not show improvement in the future. ${ }^{15,16}$ When compared with using 1-2 weeks to determine treatment response, it may be that Korean experts prefer to allow more time to pass from the initial treatment to evaluate improvement. This result was also different from those of other studies, which did not consider time for treatment response.

\section{Remission}

On remission, the results of the survey were partially different from those of the RSWG. According to the results of our survey, most respondents agreed to include the concept of social occupational function in the definition of remission. In- cluding the concept of improvement of functioning to the criteria of remission could cause confusion with the criteria of recovery. Several studies prior to the definition of the RSWG included functional improvement in the concept of remission, ${ }^{4}$ based on the notion that if symptomatic improvement is maintained for a certain period, functional improvement could also be observed. ${ }^{23}$

Instead of a score of 3 points, respondents defined a PANSS score of $\leq 2$ points (minimal) as the cutoff for positive and negative symptoms for remission. This suggests that the survey respondents in this study tended to apply stricter criteria. Chung et al. ${ }^{42}$ sought to divide the remission criteria into two different groups and use stricter cutoff and negative symptom scales, which led to a low remission rate with $20 \%$ differences between groups. In addition, using the negative symptom scale may be appropriate for studies that focus on the improvement of psychosocial function as well as symptom severity, such as longterm follow-up studies. When positive symptoms were evaluated, $53.6 \%$ of respondents considered all seven items of the PANSS positive symptoms in evaluating remission. To define remission, 56\% of the respondents set 12 months as the required duration for a symptomatically stable condition. Compared with the RSWG criteria (6 months), most experts tended to report that they would use a longer duration to define remission. These rigorous criteria for determining remission might be due to differences in individuals with FEP compared with the chronic patients that were considered by the RSWG. According to a long-term study, a high percentage (approximately 80\%) of patients remitted within 1 year. ${ }^{86} \mathrm{Al}-$ though long time criteria could reflect the heterogenous nature and long-term course of schizophrenia, Leuch $t^{3}$ suggested 3 months for defining remission out of consideration for clinical trials that need to be sufficiently long and require frequent measurements.

\section{Relapse}

Many relapse definitions have been used by numerous studies and are presented in Table 2. When we assessed the threshold for relapse, hospitalization due to aggravation of symptoms was considered a relapse. The aggravation of psychotic symptoms in a symptom-free patient after the initial episode being considered as a relapse is consistent with data reported in the literature. ${ }^{87}$ In addition, the presence of positive symptoms measured by how clinical scales rate relapses agrees with data reported in the literature. ${ }^{19,62,87,88}$ However, the definition of the minimum time necessary for the reappearance of psychiatric symptoms and worsening in disease severity and functioning was reported at 2 days in this study, whereas previous studies have reported the minimum necessary time at 2 weeks. ${ }^{87,89} \mathrm{Con}$ versely, we sought to define the duration of a stable condition 


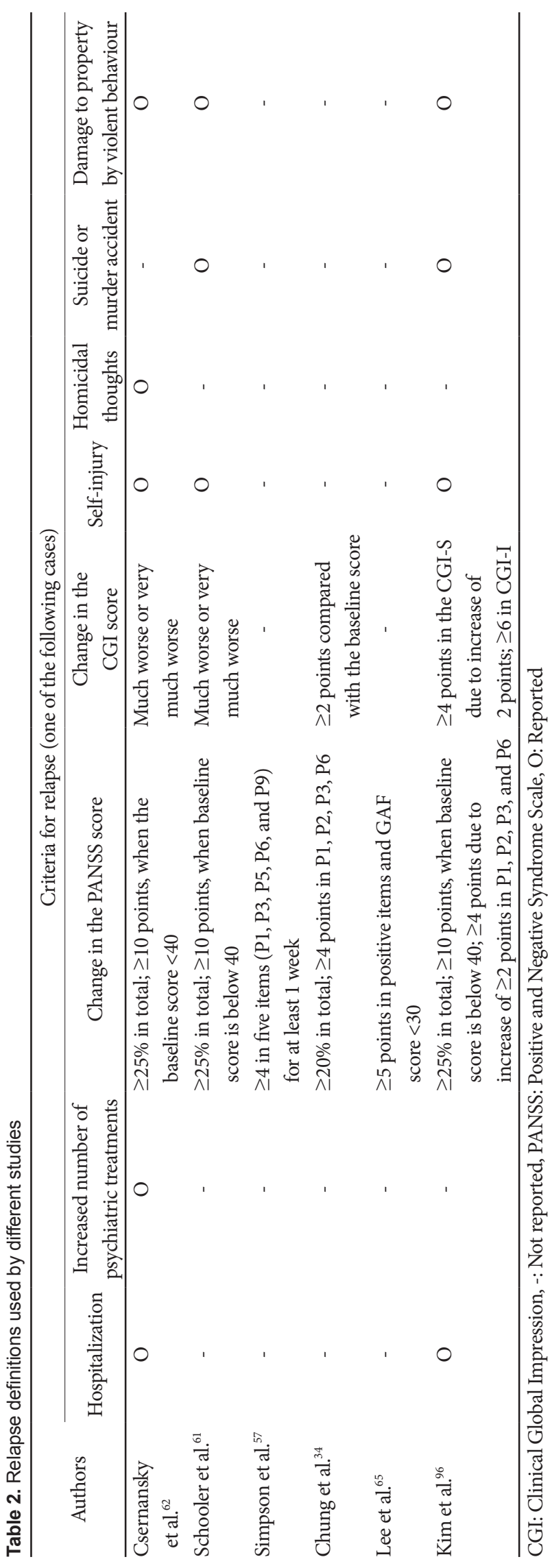

prior to relapse, and this suggested that a period of 6 months was more favorable than a period of 12 months, which is consistent with the findings of other studies. ${ }^{5}$ Few respondents agreed that an increase in the level (frequency) in the frequency of psychiatric consultations.

\section{Recovery}

Recovery has been operationalized as a multidimensional concept, incorporating symptomatic and functional improvement in the social, occupational, and educational domains, with a necessary duration component. ${ }^{4}$ The numerous trials on the definitions of recovery are presented in Table 3. The results of our survey revealed that over half the respondents did not define recovery as $<36$ points on the PANSS. This is similar to the results of previous studies, which argued that the complete elimination of symptoms has no therapeutic purpose, and restoring social function is the ultimate goal. ${ }^{74,76} \mathrm{We}$ found that the GAF and SOFAS scores were consistent with data reported in the literature. ${ }^{75}$ To identify the definitions of partial and full recovery of social function, respondents selected appropriate interpersonal relations at all age ranges, which is consistent with the findings of previous reports. ${ }^{7,90}$ Regarding these results, it is highly likely that different interpreters will have different opinions. Although there may be the capability or desire to form interpersonal relationships, it may not be possible because of the actual environment of the patient. A total of $46.5 \%$ of the respondents agreed that the definition of partial recovery in occupational function included employment for the whole period of maintaining the remission state or homemakers performing housework to some extent. Moreover, over $25 \%$ of respondents did not specify a duration for functional recovery. Conversely, $68.5 \%$ of respondents agreed that full recovery should be defined as restored appropriate occupational or academic function or homemakers performing proper housework without a specific duration. According to generally accepted views, functional remission implies proper social functioning in the main domains of everyday life: personal care, living, working, and relating to others. However, the assessment of social functioning is quite complicated. ${ }^{91,92}$ Many instruments have the drawback of assessing a mixture of instrumental performance of daily life tasks and psychopathology-related behavior instead of measuring the level of functioning in social roles relative to what one may expect based on social position and background. ${ }^{93}$ Our study suggested that Korean experts agreed with a somewhat vague concept regarding socio-occupational functioning for determining recovery without specific components. This may signify that they regard the recovery state in FEP as a state of being no different than any other member of society. However, when psychopathology was considered using the PANSS, most respondents de- 
Table 3. Recovery definitions used by different studies

\begin{tabular}{|c|c|c|}
\hline Authors & Criteria for recovery & Recovery \\
\hline McGlashan et al..$^{90}$ & $\begin{array}{l}\text { No symptoms, being employed, and maintaining a meaningful relationship with family members as the } \\
\text { normal state. }\end{array}$ & $6 \%$ \\
\hline Torgalsboen et al. ${ }^{76}$ & $\begin{array}{l}\text { Reliable diagnosis of schizophrenia, Not fulfilling criteria at present; had been out of hospital for at least } 5 \\
\text { years; present psychosocial functioning was within a "normal range" (e.g., } \geq 65 \text { on the GAS) and no } \\
\text { neuroleptic drug use or only at a low dosage ( }<1 / 2 \text { DDD). }\end{array}$ & NR \\
\hline Liberman et al. ${ }^{74}$ & $\begin{array}{l}\geq 4 \text { points on the BPRS for } 2 \text { consecutive years. Ability to successfully hold at least a part-time job or } \\
\text { successfully attend school at least part-time for } 2 \text { consecutive years. During the age of retirement, } \\
\text { participating actively in recreational, family, or volunteer activities. Living independently without } \\
\text { day-to-day supervision for money management, shopping, food preparation, laundry, personal hygiene, } \\
\text { or need for structured recreational or vocational activities. Ability to initiate own activities and schedule } \\
\text { one's time without reminders from family or other caregivers. While most individuals will be living on } \\
\text { their own or with a roommate, partner, or friend, some individuals could meet this criterion if they are } \\
\text { living at home with family if that is considered culturally and age appropriate. The individual may be } \\
\text { receiving disability benefits as long as he/she is participating constructively in instrumental activities for } \\
\text { half or more of the total duration. In the context of the individual's cultural background and given the } \\
\text { constraints of geographical distance and socio-economic factors, the individual has cordial relations with } \\
\text { his/her family. This may be limited to phone calls, correspondence, or occasional visits (e.g., on holidays } \\
\text { and family events). At least once per week, having a meeting, social event, meal, recreational activity, phone } \\
\text { conversation. or other ioint interaction with a peer outside of the family }\end{array}$ & NR \\
\hline
\end{tabular}

Modestin et al. ${ }^{97} \quad$ Full employment, reassumed social roles, and no psychosis symptoms on examination except for some eccentricity or symptom residue for 5 years

Robinson et al. ${ }^{77} \quad$ For 2 consecutive years: no worse than mild in some SADS-C and in some SANS items, appropriate role functioning ability to perform day-to-day living tasks without supervision, social interactions.

Harrow et al. ${ }^{80} \quad$ Absence of major symptoms throughout the follow-up year (absence of psychosis activity and absence of negative symptoms), adequate psychosocial functioning, including instrumental (or paid) work for at least half of the time during the follow-up year, and absence of a very poor social activity level, no psychiatric re-hospitalization during the follow-up year.

Lauronen et al. ${ }^{75} \quad$ For full recovery, 1 or 2 points on the CGI, $\geq 71$ points on the SOFAS, $\leq 36$ total score on the PANSS, $\leq 2$ points in each item of the positive or negative scale of the PANSS, no psychiatric hospitalizations during the last 2 years of follow-up, no or low-dose antipsychotic medication at the study moment, ability to work. For partial recovery, 1 or 2 points on the CGI, $\leq 36$ total score on the PANSS, $\geq 61$ points on the SOFAS

Jaaskelainen et al. ${ }^{98}$ Having improvements in both the clinical and social domains, with improvements in at least one of the domains persisting for at least 2 years, and current symptoms no worse than mild.

Full in Kim et al. ${ }^{96} \quad$ Five items maintained for $\geq 1$ year: all psychosis (P1, P2, P3, G5, G9) and negative (N1, N4, N6) items of the PANSS $\leq 2$ (minimal); SOFAS score $\geq 71$; appropriate social functions maintained (active meeting with an acquaintance more than twice a month, but meeting by accident or seeing or greeting at a church are excluded); appropriate occupational functions maintained, such as employment for at least half of the standard period (regardless of type of employment), job-seeking activities, students going to school/library on a regular basis, or homemakers taking appropriate responsibility for household chores.

Partial in Kim et al. ${ }^{96}$ Five items maintained for $\geq 1$ year: all psychosis (P1, P2, P3, G5, G9) and negative (N1, N4, N6) items of PANSS $\leq 3$ (mild); SOFAS score $\geq 61$; appropriate social functions maintained (active meeting with an acquaintance more than once a month or conversation over the phone more than twice a month (texting or SMS are excluded); and appropriate occupational functions maintained, such as employment for at least one third of the standard period, job-seeking activities, students going to school/library on a regular basis, or homemakers taking appropriate responsibility for household chores.

NR: Not reported, GAS: Global Assessment Scale, DDD: Defined Daily Doses, BPRS: Brief Psychiatric Rating Scale; CGI: Clinical Global Impression, SOFAS: Social and Occupational Functioning Assessment Scale, PANSS: Positive and Negative Syndrome Scale, SADS-C: the Schedule of Affective Disorders and Schizophrenia-Change Version, SANS: the Scale for the Assessment of Negative Symptom 
fined $\leq 3$ points (mild) as partial recovery. Nonetheless, $86.3 \%$ of respondents defined no symptoms as full recovery.

Considering psychopathology, dosage of medication, and the CGI scale, the guidelines suggested by our Korean experts were somewhat strict compared with other definitions. This can be explained by our specificity of assessing FEP. On the duration of recovery, our results showed that it should be set at 1 year, which is consistent with the proposal by Lally et al., ${ }^{4}$ but other study has suggested 2 years for recovery. ${ }^{93}$ When defining recovery based on the medication dose, many Korean experts agreed that a chlorpromazine equivalent of $\leq 300 \mathrm{mg}$ (risperidone $3 \mathrm{mg}$ ) and no medication indicated partial and full recovery, respectively. This medication dose was equal to those previously reported. ${ }^{94}$ There have been suggestions that recovery should be determined not only based on symptomatic and functional remission but also based on the absence of medication. ${ }^{7495}$ Son et al. ${ }^{94}$ suggested that antipsychotic treatment discontinuation in an individual who has achieved functional recovery after a single psychotic episode is associated with a high risk of symptom recurrence. Future studies should assess patients with FEP prescribed a low dosage or no medication in a medication discontinuation study.

\section{Limitations}

It is of note that a small number of experts participated in the survey. This may have excluded many opinions of experts with sufficient experience in the field of FEP. Furthermore, it is not common for the PANSS or related objective instruments to be administered in routine clinical practice in Korea. Most general and psychiatric training hospitals have a residency program for psychiatrists. Fortunately, the respondents' working environment was biased toward general and psychiatric hospitals and were often exposed to incidents of psychosis and objective instruments for assessing the symptoms of psychosis. Although general psychometric properties cannot be examined with the CGI scale, one alternative would be to replace the PANSS with the CGI score that can be quickly and easily evaluated. ${ }^{3}$ It should also be noted that this study identified what experts considered as intrinsic factors for each definition; however, some respondents misinterpreted the question itself as a definition. In addition, it is likely that the profile of agreed aspects of the operational definitions of treatment outcome for individuals with FEP may differ among countries; therefore, the exclusivity of the Korean-based sample is also a limitation. The decision regarding the selection of items and the formulation of questions was subjective and taken by several members of the expert panel, which may reflect the areas with highest personal experience or the clinical setting in which more studies have been performed. While experts' opinions collected in a consensus as in this study have a low grade of evidence, we consider this study as a step in a long process to reach the level of evidence required due to the absence of other types of assessment.

In conclusion, as shown in Table 1 , each criterion for the definitions of clinical outcomes was suggested using a survey. Each definition consists of the extent of the reduction in psychopathology, socio-occupational functioning, and the duration of each state.

The results of this study are outcomes obtained from various discussions and consultations after we reviewed domestic and foreign literature regarding the clinical evaluations of FEP, followed by a collection of informed opinions from Korean experts. Therefore, these results may improve the interpretation of assessment measures in FEP research. We hope that these can be widely shared among psychiatrists and play a significant role in the clinical care of patients with FEP.

\section{Supplementary Materials}

The online-only Data Supplement is available with this article at https://doi.org/10.30773/pi.2019.0240.

\section{Acknowledgments}

This research was supported by a grant of the Korean Mental Health Technology R\&D Project, Ministry of Health \& Welfare, Republic of Korea (HM14C2608) and a grant of the Korea Health Technology R\&D Project through the Korea Health Industry Development Institute (KHIDI), funded by the Ministry of Health \& Welfare, Republic of Korea (HI18C2383).

\section{Conflicts of Interest}

The authors have no potential conflicts of interest to disclose.

\section{Author Contributions}

Conceptualization: Young-Chul Chung. Data curation: Kunhyung Kim, Bong Ju Lee. Formal analysis: Kunhyung Kim. Funding acquisition: YoungChul Chung. Investigation: Young-Chul Chung, Bong Ju Lee. Methodology: Young-Chul Chung, Sung-Wan Kim, Bong Ju Lee. Project administration: Young-Chul Chung, Yang Hong Piao. Resources: Sung-Wan Kim, Jung Jin Kim, Je-Chun Yu, Kyu Young Lee, Seung-Hee Won, Seung-Hwan Lee, Seung-Hyun Kim, Shi Hyun Kang, Euitae Kim. Software: Kunhyung Kim. Supervision: Young-Chul Chung. Validation: Young-Chul Chung, Bong Ju Lee. Visualization: Kunhyung Kim, Bong Ju Lee. Writing-original draft: Bong Ju Lee. Writing-review \& editing: Young-Chul Chung, Bong Ju Lee.

\section{ORCID iDs}

Bong Ju Lee Sung-Wan Kim

Jung Jin Kim

Je-Chun Yu

Kyu Young Lee

Seung-Hee Won

Seung-Hwan Lee

Seung-Hyun Kim

Shi Hyun Kang

Euitae Kim

Kunhyung Kim

Yang Hong Piao

https://orcid.org/0000-0002-4194-6842 https://orcid.org/0000-0002-6739-2163 https://orcid.org/0000-0003-3899-5579 https://orcid.org/0000-0003-1665-0289 https://orcid.org/0000-0003-3214-6082 https://orcid.org/0000-0002-4858-6173 https://orcid.org/0000-0003-0305-3709 https://orcid.org/0000-0002-2189-4600 https://orcid.org/0000-0001-8712-5698 https://orcid.org/0000-0003-0914-2331 https://orcid.org/0000-0001-9060-7233 https://orcid.org/0000-0002-0353-672X

Young-Chul Chung https://qa.orcid.org/0000-0001-8193-3029 


\section{REFERENCES}

1. Patel KR, Cherian J, Gohil K, Atkinson D. Schizophrenia: overview and treatment options. P T 2014;39:638-645.

2. Leucht S, Davis JM, Engel RR, Kane JM, Wagenpfeil S. Defining 'response'in antipsychotic drug trials: recommendations for the use of scale-derived cutoffs. Neuropsychopharmacology 2007;32:1903-1910.

3. Leucht S. Measurements of response, remission, and recovery in schizophrenia and examples for their clinical application. J Clin Psychiatry 2014;75(Suppl 1):8-14.

4. Lally J, Ajnakina O, Stubbs B, Cullinane M, Murphy KC, Gaughran F, et al. Remission and recovery from first-episode psychosis in adults: systematic review and meta-analysis of long-term outcome studies. $\mathrm{Br}$ J Psychiatry 2017;211:350-358.

5. San L, Serrano M, Canas F, Romero SL, Sanchez-Cabezudo A, Villar M. Towards a pragmatic and operational definition of relapse in schizophrenia: A Delphi consensus approach. Int J Psychiatry Clin Pract 2015;19:90-98.

6. Kay SR, Fiszbein A, Opler LA. The positive and negative syndrome scale (PANSS) for schizophrenia. Schizophr Bull 1987;13:261-276.

7. Overall JE, Gorham DR. The Brief Psychiatric Rating Scale (BPRS): recent developments in ascertainment and scaling. Psychopharmacol Bull 1988;24:97-99.

8. Andreasen NC. The Scale for the Assessment of Negative Symptoms (SANS): conceptual and theoretical foundations. Br J Psychiatry Suppl 1989;(7):49-58.

9. National Institute of Mental Health (NIMH). Clinical global impressions. Psychopharmacol Bull 1985;21:839-843.

10. Leucht S, Kane JM, Kissling W, Hamann J, Etschel E, Engel R. Clinical implications of Brief Psychiatric Rating Scale scores. Br J Psychiatry 2005; 187:366-371.

11. Correll CU, Kishimoto T, Nielsen J, Kane JM. Quantifying clinical relevance in the treatment of schizophrenia. Clin Ther 2011;33:B16-B39.

12. Kinon BJ, Chen L, Ascher-Svanum H, Stauffer VL, Kollack-Walker S, Sniadecki JL, et al. Predicting response to atypical antipsychotics based on early response in the treatment of schizophrenia. Schizophr Res 2008; 102:230-240.

13. Correll CU, Malhotra AK, Kaushik S, McMeniman M, Kane JM. Early prediction of antipsychotic response in schizophrenia. Am J Psychiatry 2003;160:2063-2065.

14. Loebel A, Citrome L, Correll CU, Xu J, Cucchiaro J, Kane JM. Treatment of early non-response in patients with schizophrenia: assessing the efficacy of antipsychotic dose escalation. BMC Psychiatry 2015;15: 271.

15. Gallego JA, Robinson DG, Sevy SM, Napolitano B, McCormack J, Lesser ML, et al. Time to treatment response in first-episode schizophrenia: should acute treatment trials last several months? J Clin Psychiatry 2011;72:1691-1696.

16. Emsley R, Rabinowitz J, Medori R. Time course for antipsychotic treatment response in first-episode schizophrenia. Am J Psychiatry 2006; 163:743-745.

17. Samara MT, Nikolakopoulou A, Salanti G, Leucht S. How many patients with schizophrenia do not respond to antipsychotic drugs in the short term? An analysis based on individual patient data from randomized controlled trials. Schizophr Bull 2019;45:639-646.

18. Lieberman J, Jody D, Geisler S, Alvir J, Loebel A, Szymanski S, et al. Time course and biologic correlates of treatment response in first-episode schizophrenia. Arch Gen Psychiatry 1993;50:369-376.

19. Wunderink L, Nienhuis FJ, Sytema S, Slooff CJ, Knegtering R, Wiersma D. Guided discontinuation versus maintenance treatment in remitted first-episode psychosis: relapse rates and functional outcome. J Clin Psychiatry 2007;68:654-661.

20. Perkins D, Lieberman J, Gu H, Tohen M, McEvoy J, Green A, et al. Predictors of antipsychotic treatment response in patients with firstepisode schizophrenia, schizoaffective and schizophreniform disor- ders. Br J Psychiatry 2004;185:18-24

21. Eaton WW, Thara R, Federman E, Tien A. Remission and relapse in schizophrenia: the Madras Longitudinal Study. J Nerv Ment Dis 1998; 186:357-363.

22. Ho BC, Andreasen NC, Flaum M, Nopoulos P, Miller D. Untreated initial psychosis: its relation to quality of life and symptom remission in first-episode schizophrenia. Am J Psychiatry 2000;157:808-815.

23. Andreasen NC, Carpenter WT Jr, Kane JM, Lasser RA, Marder SR, Weinberger DR. Remission in schizophrenia: proposed criteria and rationale for consensus. Am J Psychiatry 2005;162:441-449.

24. Menezes NM, Arenovich T, Zipursky RB. A systematic review of longitudinal outcome studies of first-episode psychosis. Psychol Med 2006;36:1349-1362.

25. AlAqeel B, Margolese HC. Remission in schizophrenia: critical and systematic review. Harv Rev Psychiatry 2012;20:281-297.

26. Chung YC, Cho GH Park TW. Treatment response, remission and recovery in schizophrenia: definition and criteria. Korean J Psychopharmacol 2006;17:5-12.

27. Leucht S, Kane JM. Measurement-based psychiatry: definitions of response, remission, stability, and relapse in schizophrenia. J Clin Psychiatry 2006;67:1813-1814.

28. Obermeier M, Schennach-Wolff R, Meyer S, Moller HJ, Riedel M, Krause D, et al. Is the PANSS used correctly? a systematic review. BMC Psychiatry 2011;11:113.

29. McCue RE, Waheed R, Urcuyo L, Orendain G, Joseph MD, Charles R, et al. Comparative effectiveness of second-generation antipsychotics and haloperidol in acute schizophrenia. Br J Psychiatry 2006;189:433440.

30. Lieberman JA, Stroup TS, McEvoy JP, Swartz MS, Rosenheck RA, Perkins DO, et al. Effectiveness of antipsychotic drugs in patients with chronic schizophrenia. N Engl J Med 2005;353:1209-1223.

31. Robinson DG, Woerner MG, Alvir JM, Geisler S, Koreen A, Sheitman $\mathrm{B}$, et al. Predictors of treatment response from a first episode of schizophrenia or schizoaffective disorder. Am J Psychiatry 1999;156:544-549.

32. Emsley RA. Partial response to antipsychotic treatment: the patient with enduring symptoms. J Clin Psychiatry 1999;60(Suppl 23):10-13.

33. Chakos M, Lieberman J, Hoffman E, Bradford D, Sheitman B. Effectiveness of second-generation antipsychotics in patients with treatmentresistant schizophrenia: a review and meta-analysis of randomized trials. Am J Psychiatry 2001;158:518-526.

34. Chung SC, Cho SJ, Kim CH, Bahk WM, Yoon JS, Chung IW, et al. Effectiveness and tolerability of long-acting risperidone: a 12 weeks, multi-center switching study from oral antipsychotics. Korean J Psychopharmacol 2005;16:109-120.

35. Green AI, Tohen MF, Hamer RM, Strakowski SM, Lieberman JA, Glick I, et al. First episode schizophrenia-related psychosis and substance use disorders: acute response to olanzapine and haloperidol. Schizophr Res 2004;66:125-135.

36. Emsley RA. Risperidone in the treatment of first-episode psychotic patients: a double-blind multicenter study. Risperidone Working Group. Schizophr Bull 1999;25:721-729.

37. Gasquet I, Tcherny-Lessenot S, Lepine JP, Falissard B. Patient satisfaction with psychotropic drugs: sensitivity to change and relationship to clinical status, quality-of-life, compliance and effectiveness of treatment. Results from a nation-wide 6-month prospective study. Eur Psychiatry 2006;21:531-538.

38. Beasley CM, Jr., Hamilton SH, Crawford AM, Dellva MA, Tollefson GD, Tran PV, et al. Olanzapine versus haloperidol: acute phase results of the international double-blind olanzapine trial. Eur Neuropsychopharmacol 1997;7:125-137.

39. Breier A, Buchanan RW, Irish D, Carpenter WT Jr. Clozapine treatment of outpatients with schizophrenia: outcome and long-term response patterns. 1993. Psychiatr Serv 2000;51:1249-1253.

40. Kane J, Honigfeld G, Singer J, Meltzer H. Clozapine for the treatmentresistant schizophrenic. A double-blind comparison with chlorproma- 
zine. Arch Gen Psychiatry 1988;45:789-796.

41. Amminger GP, Resch F, Mutschlechner R, Friedrich MH, Ernst E. Premorbid adjustment and remission of positive symptoms in first-episode psychosis. Eur Child Adolesc Psychiatry 1997;6:212-218.

42. Chung SB, Bhak WM, Kwon JS, Kang SH, Joo YH, Ahn JH, et al. Remission rates and criteria for clinical studies on schizophrenia. Korean J Psychopharmacol 2007;18:231-239.

43. Stauffer VL, Case M, Kinon BJ, Conley R, Ascher-Svanum H, KollackWalker S, et al. Early response to antipsychotic therapy as a clinical marker of subsequent response in the treatment of patients with firstepisode psychosis. Psychiatry Res 2011;187:42-48.

44. Leucht S, Davis JM, Engel RR, Kissling W, Kane JM. Definitions of response and remission in schizophrenia: recommendations for their use and their presentation. Acta Psychiatr Scand Suppl 2009;(438):7-14.

45. Curtis CE, Calkins ME, Grove WM, Feil KJ, Iacono WG. Saccadic disinhibition in patients with acute and remitted schizophrenia and their first-degree biological relatives. Am J Psychiatry 2001;158:100-106.

46. Yen CF, Chen CS, Yeh ML, Yen JY, Ker JH, Yang SJ. Comparison of insight in patients with schizophrenia and bipolar disorder in remission. J Nerv Ment Dis 2002;190:847-849.

47. Loebel AD, Lieberman JA, Alvir JM, Mayerhoff DI, Geisler SH, Szymanski SR. Duration of psychosis and outcome in first-episode schizophrenia. Am J Psychiatry 1992;149:1183-1188.

48. Larsen TK, Moe LC, Vibe-Hansen L, Johannessen JO. Premorbid functioning versus duration of untreated psychosis in 1 year outcome in first-episode psychosis. Schizophr Res 2000;45:1-9.

49. Malla AK, Norman RM, Manchanda R, McLean TS, Harricharan R, Cortese L, et al. Status of patients with first-episode psychosis after one year of phase-specific community-oriented treatment. Psychiatr Serv 2002;53:458-463.

50. Mayerhoff DI, Loebel AD, Alvir JM, Szymanski SR, Geisler SH, Borenstein $\mathrm{M}$, et al. The deficit state in first-episode schizophrenia. Am J Psychiatry 1994;151:1417-1422.

51. Addington J, Leriger E, Addington D. Symptom outcome 1 year after admission to an early psychosis program. Can J Psychiatry 2003;48: 204-207.

52. Auslander LA, Jeste DV. Sustained remission of schizophrenia among community-dwelling older outpatients. Am J Psychiatry 2004;161: 1490-1493.

53. Wiersma D, Nienhuis FJ, Slooff CJ, Giel R. Natural course of schizophrenic disorders: a 15-year followup of a Dutch incidence cohort. Schizophr Bull 1998;24:75-85.

54. Huber G, Gross G, Schuttler R, Linz M. Longitudinal studies of schizophrenic patients. Schizophr Bull 1980;6:592-605.

55. Singh SP, Burns T, Amin S, Jones PB, Harrison G. Acute and transient psychotic disorders: precursors, epidemiology, course and outcome. $\mathrm{Br}$ J Psychiatry 2004;185:452-459.

56. van Os J, Burns T, Cavallaro R, Leucht S, Peuskens J, Helldin L, et al. Standardized remission criteria in schizophrenia. Acta Psychiatr Scand 2006;113:91-95.

57. Simonsen E, Friis S, Haahr U, Johannessen JO, Larsen TK, Melle I, et al. Clinical epidemiologic first-episode psychosis: 1-year outcome and predictors. Acta Psychiatr Scand 2007;116:54-61.

58. Bobes J, Ciudad A, Alvarez E, San L, Polavieja P, Gilaberte I. Recovery from schizophrenia: results from a 1-year follow-up observational study of patients in symptomatic remission. Schizophr Res 2009;115:58-66.

59. Robinson D, Woerner MG, Alvir JM, Bilder R, Goldman R, Geisler S, et al. Predictors of relapse following response from a first episode of schizophrenia or schizoaffective disorder. Arch Gen Psychiatry 1999; 56:241-247.

60. Fleischhacker WW, Keet IP, Kahn RS; EUFEST Steering Committee. The European First Episode Schizophrenia Trial (EUFEST): rationale and design of the trial. Schizophr Res 2005;78:147-156.

61. Schooler N, Rabinowitz J, Davidson M, Emsley R, Harvey PD, Kopala $\mathrm{L}$, et al. Risperidone and haloperidol in first-episode psychosis: a long- term randomized trial. Am J Psychiatry 2005;162:947-953.

62. Csernansky JG, Mahmoud R, Brenner R; Risperidone-USA-79 Study Group. A comparison of risperidone and haloperidol for the prevention of relapse in patients with schizophrenia. N Engl J Med 2002;346: $16-22$.

63. Arato M, O'Connor R, Meltzer HY; ZEUS Study Group. A 1-year, double-blind, placebo-controlled trial of ziprasidone 40,80 and $160 \mathrm{mg} /$ day in chronic schizophrenia: the Ziprasidone Extended Use in Schizophrenia (ZEUS) study. Int Clin Psychopharmacol 2002;17:207-215.

64. Chrzanowski WK, Marcus RN, Torbeyns A, Nyilas M, McQuade RD. Effectiveness of long-term aripiprazole therapy in patients with acutely relapsing or chronic, stable schizophrenia: a 52-week, open-label comparison with olanzapine. Psychopharmacology (Berl) 2006;189:259266.

65. Lee SH, Choi TK, Suh S, Kim YW, Kim B, Lee E, et al. Effectiveness of a psychosocial intervention for relapse prevention in patients with schizophrenia receiving risperidone via long-acting injection. Psychiatry Res 2010;175:195-199.

66. Altamura AC, Bassetti R, Sassella F, Salvadori D, Mundo E. Duration of untreated psychosis as a predictor of outcome in first-episode schizophrenia: a retrospective study. Schizophr Res 2001;52:29-36.

67. The Scottish first episode schizophrenia study. VIII. Five-year followup: clinical and psychosocial findings. The Scottish Schizophrenia Research Group. Br J Psychiatry 1992;161:496-500.

68. Bhugra D, Hilwig M, Hossein B, Marceau H, Neehall J, Leff J, et al. First-contact incidence rates of schizophrenia in Trinidad and one-year follow-up. Br J Psychiatry 1996;169:587-592.

69. Marneros A, Pillmann F, Haring A, Balzuweit S, Bloink R. What is schizophrenic in acute and transient psychotic disorder? Schizophr Bull 2003;29:311-323.

70. Jager MDM, Hintermayr M, Bottlender R, Strauss A, Moller HJ. Course and outcome of first-admitted patients with acute and transient psychotic disorders (ICD-10:F23). Focus on relapses and social adjustment. Eur Arch Psychiatry Clin Neurosci 2003;253:209-215.

71. Gaebel W, Moller HJ, Buchkremer G, Ohmann C, Riesbeck M, Wolwer W, et al. Pharmacological long-term treatment strategies in first episode schizophrenia--study design and preliminary results of an ongoing RCT within the German Research Network on Schizophrenia. Eur Arch Psychiatry Clin Neurosci 2004;254:129-140.

72. Kramer M, Simpson G, Maciulis V, Kushner S, Vijapurkar U, Lim P, et al. Paliperidone extended-release tablets for prevention of symptom recurrence in patients with schizophrenia: a randomized, doubleblind, placebo-controlled study. J Clin Psychopharmacol 2007;27:6-14.

73. Pigott TA, Carson WH, Saha AR, Torbeyns AF, Stock EG, Ingenito $\mathrm{GG}$, et al. Aripiprazole for the prevention of relapse in stabilized patients with chronic schizophrenia: a placebo-controlled 26-week study. J Clin Psychiatry 2003;64:1048-1056.

74. Liberman RP, Kopelowicz A, Ventura J, Gutkind D. Operational criteria and factors related to recovery from schizophrenia. Int Rev Psychiatry 2002;14:256-272.

75. Lauronen E, Koskinen J, Veijola J, Miettunen J, Jones PB, Fenton WS, et al. Recovery from schizophrenic psychoses within the northern Finland 1966 Birth Cohort. J Clin Psychiatry 2005;66:375-383.

76. Torgalsboen AK. Full recovery from schizophrenia: the prognostic role of premorbid adjustment, symptoms at first admission, precipitating events and gender. Psychiatry Res 1999;88:143-152.

77. Robinson DG, Woerner MG, McMeniman M, Mendelowitz A, Bilder RM. Symptomatic and functional recovery from a first episode of schizophrenia or schizoaffective disorder. Am J Psychiatry 2004;161: 473-479.

78. Harrison G, Hopper K, Craig T, Laska E, Siegel C, Wanderling J, et al. Recovery from psychotic illness: a 15- and 25-year international followup study. Br J Psychiatry 2001;178:506-517.

79. Onken SJ, Craig CM, Ridgway P, Ralph RO, Cook JA. An analysis of the definitions and elements of recovery: a review of the literature. 
Psychiatr Rehabil J 2007;31:9-22.

80. Harrow M, Grossman LS, Jobe TH, Herbener ES. Do patients with schizophrenia ever show periods of recovery? A 15-year multi-followup study. Schizophr Bull 2005;31:723-734.

81. Drake RE, McHugo GJ, Xie H, Fox M, Packard J, Helmstetter B. Tenyear recovery outcomes for clients with co-occurring schizophrenia and substance use disorders. Schizophr Bull 2006;32:464-473.

82. Liberman RP, Kopelowicz A. Recovery from schizophrenia: a concept in search of research. Psychiatr Serv 2005;56:735-742.

83. Hall RC. Global assessment of functioning. A modified scale. Psychosomatics 1995;36:267-275.

84. Goldman HH, Skodol AE, Lave TR. Revising axis V for DSM-IV: a review of measures of social functioning. Am J Psychiatry 1992;149: 1148-1156.

85. Shafer A, Dazzi F. Meta-analysis of the positive and Negative Syndrome Scale (PANSS) factor structure. J Psychiatr Res 2019;115:113-120.

86. Lieberman JA, Phillips M, Gu H, Stroup S, Zhang P, Kong L, et al. Atypical and conventional antipsychotic drugs in treatment-naive first-episode schizophrenia: a 52-week randomized trial of clozapine vs chlorpromazine. Neuropsychopharmacology 2003;28:995-1003.

87. Emsley R, Chiliza B, Asmal L, Harvey BH. The nature of relapse in schizophrenia. BMC Psychiatry 2013;13:50.

88. Leucht S, Barnes TR, Kissling W, Engel RR, Correll C, Kane JM. Relapse prevention in schizophrenia with new-generation antipsychotics: a systematic review and exploratory meta-analysis of randomized, controlled trials. Am J Psychiatry 2003;160:1209-1222.

89. Olivares JM, Sermon J, Hemels M, Schreiner A. Definitions and drivers of relapse in patients with schizophrenia: a systematic literature review. Ann Gen Psychiatry 2013;12:32.
90. McGlashan TH. The Chestnut Lodge follow-up study. II. Long-term outcome of schizophrenia and the affective disorders. Arch Gen Psychiatry 1984;41:586-601.

91. Link BG, Mesagno FP, Lubner ME, Dohrenwend BP. Problems in measuring role strains and social functioning in relation to psychological symptoms. J Health Soc Behav 1990;31:354-369.

92. Bellack AS, Green MF, Cook JA, Fenton W, Harvey PD, Heaton RK, et al. Assessment of community functioning in people with schizophrenia and other severe mental illnesses: a white paper based on an NIMHsponsored workshop. Schizophr Bull 2007;33:805-822.

93. Wunderink L, Sytema S, Nienhuis FJ, Wiersma D. Clinical recovery in first-episode psychosis. Schizophr Bull 2009;35:362-369.

94. Mayoral-van Son J, de la Foz VO, Martinez-Garcia O, Moreno T, Parrilla-Escobar M, Valdizan EM, et al. Clinical outcome after antipsychotic treatment discontinuation in functionally recovered first-episode nonaffective psychosis individuals: a 3-year naturalistic follow-up study. J Clin Psychiatry 2016;77:492-500.

95. Wyatt RJ, Damiani LM, Henter ID. First-episode schizophrenia. Early intervention and medication discontinuation in the context of course and treatment. Br J Psychiatry Suppl 1998;172:77-83.

96. Kim SW, Lee BJ, Kim JJ, Yu JC, Lee KY, Won SH, et al. Design and methodology of the Korean early psychosis cohort study. Psychiatry Investig 2017;14:93-99.

97. Modestin J, Huber A, Satirli E, Malti T, Hell D. Long-term course of schizophrenic illness: Bleuler's study reconsidered. Am J Psychiatry 2003;160:2202-2208.

98. Jaaskelainen E, Juola P, Hirvonen N, McGrath JJ, Saha S, Isohanni M, et al. A systematic review and meta-analysis of recovery in schizophrenia. Schizophr Bull 2013;39:1296-1306. 
Supplementary Table 1. Frequency distribution of questionnaire in treatment response

\begin{tabular}{|c|c|c|c|c|c|c|c|c|c|}
\hline \multirow{2}{*}{ Items } & \multirow{2}{*}{$\mathrm{N}$} & \multicolumn{6}{|c|}{ Likert scale, frequency (\%) } & \multirow{2}{*}{ Mean \pm SD } & \multirow{2}{*}{$\mathrm{p}$ value } \\
\hline & & 0 & 1 & 2 & 3 & 4 & 5 & & \\
\hline \multicolumn{10}{|l|}{ 1. Evaluation for treatment response } \\
\hline Positive symptoms only & 82 & $14(17.1)$ & $9(11.0)$ & $12(14.6)$ & $31(37.8)$ & $11(13.4)$ & $5(6.1)$ & $2.38 \pm 1.46$ & \multirow[t]{2}{*}{$<0.001^{*}$} \\
\hline Positive and negative symptoms simultaneously & 90 & $0(0.0)$ & $1(1.1)$ & $1(1.1)$ & $7(7.8)$ & $16(17.8)$ & $65(72.2)$ & $4.59 \pm 0.78$ & \\
\hline \multicolumn{10}{|l|}{ 2. PANSS total score } \\
\hline - $\geq 20 \%$ decrease from baseline score & 89 & $6(6.7)$ & $10(11.2)$ & $21(23.6)$ & $42(47.2)$ & $5(5.6)$ & $5(5.6)$ & $2.51 \pm 1.16 \mathrm{a}^{\dagger}$ & \multirow[t]{3}{*}{$<0.001^{\dagger}$} \\
\hline$\cdot \geq 30 \%$ decrease from baseline score & 89 & $2(2.2)$ & $1(1.1)$ & $6(6.7)$ & $26(29.2)$ & $40(44.9)$ & $14(15.7)$ & $3.61 \pm 1.02 b$ & \\
\hline - $\geq 50 \%$ decrease from baseline score & 90 & $0(0.0)$ & $1(1.1)$ & $8(8.9)$ & $21(23.3)$ & $29(32.2)$ & $31(34.4)$ & $3.90 \pm 1.02 \mathrm{~b}$ & \\
\hline \multicolumn{10}{|l|}{ 3. CGI-I } \\
\hline $\begin{array}{l}\text { - Improved to } 2 \text { points or more in the case of the } \\
\text { baseline CGI-S is } 4 \text { points (moderate) or more, } \\
\text { and improved to } 3 \text { points or more in case of the } \\
\text { baseline CGI-S is } 3\end{array}$ & 88 & $0(0.0)$ & $0(0.0)$ & $5(5.7)$ & $11(12.5)$ & $52(59.1)$ & $20(22.7)$ & $3.99 \pm 0.77$ & \multirow[t]{2}{*}{$0.453^{*}$} \\
\hline - Improved to more than 2 points & 89 & $0(0.0)$ & $1(1.1)$ & $3(3.4)$ & $23(25.8)$ & $39(43.8)$ & $23(25.8)$ & $3.90 \pm 0.87$ & \\
\hline
\end{tabular}

Data are presented as N (\%) and mean \pm standard deviation. ${ }^{*} \mathrm{p}$ values were derived from Mann-Whitney's U test, ${ }^{\dagger} \mathrm{p}$ values were derived from Kruskal-Wallis test and Dunn's post-hoc test was used for multiple comparisons. Means with different scripts are different from each other $(\mathrm{p}<0.05)$. M: mean, SD: standard deviation, PANSS: positive and negative syndrome of scale, CGI-I: clinical global impression-improvement 
Supplementary Table 2. Frequency distribution of the ranked choice questions for 'treatment response' evaluation responded by psychiatrists

\begin{tabular}{cccccc}
\hline \multirow{2}{*}{$\begin{array}{c}\text { Items for considering psychiatric } \\
\text { symptoms in PANSS }\end{array}$} & 1st choice & 2nd choice & 3rd choice & 4th choice & \multirow{2}{*}{ Weighted average* } \\
\cline { 2 - 5 } All 7 PANSS positive items & $36(42.9)$ & $17(20.5)$ & $29(34.5)$ & $7(8.6)$ & 2.92 \\
5 items (P1, P2, P3, P5, P6) & $7(8.3)$ & $38(45.8)$ & $18(21.4)$ & $19(23.5)$ & 2.40 \\
4 items (P1, P2, P3, P6) & $8(9.5)$ & $26(31.3)$ & $27(32.1)$ & $21(25.9)$ & 2.26 \\
4 items (P1, P3, P6, G9) & $33(39.3)$ & $2(2.4)$ & $10(11.9)$ & $34(42.0)$ & 2.43 \\
\hline
\end{tabular}

*each rank 1st, 2nd, 3rd, 4th priority set to $4,3,2,1$ point 
Supplementary Table 3. Frequency distribution of questionnaire on remission

\begin{tabular}{|c|c|c|c|c|c|c|c|c|c|}
\hline \multirow{2}{*}{ Items } & \multirow{2}{*}{$\mathrm{N}$} & \multicolumn{6}{|c|}{ Likert scale, frequency $(\%)$} & \multirow{2}{*}{ Mean \pm SD } & \multirow{2}{*}{$\mathrm{p}$ value } \\
\hline & & 0 & 1 & 2 & 3 & 4 & 5 & & \\
\hline 1. Agree with including socio-occupational functioning & 91 & $1(1.1)$ & $2(2.2)$ & $3(3.3)$ & $15(16.5)$ & $32(35.2)$ & $38(41.8)$ & $4.08 \pm 1.05$ & - \\
\hline \multicolumn{10}{|l|}{ 2. Severity of positive and negative symptoms in PANSS } \\
\hline - 3 points or less (mild) & 91 & $2(2.2)$ & $4(4.4)$ & $8(8.8)$ & $34(37.4)$ & $29(31.9)$ & $14(15.4)$ & $3.38 \pm 1.12$ & \multirow{2}{*}{$<0.001^{*}$} \\
\hline - 2 points or less (minimal) & 90 & $0(0.0)$ & $0(0.0)$ & $2(2.2)$ & $13(14.4)$ & $29(32.2)$ & $46(51.1)$ & $4.32 \pm 0.80$ & \\
\hline 4. Using SANS for evaluation of negative symptoms & 90 & $2(2.2)$ & $2(2.2)$ & $3(3.3)$ & $29(32.2)$ & $36(40.0)$ & $18(20.0)$ & $3.66 \pm 1.05$ & - \\
\hline \multicolumn{10}{|l|}{ 5. Severity of negative symptoms in SANS } \\
\hline - 3 points or less(moderate) & 86 & $1(1.2)$ & $4(4.7)$ & $9(10.5)$ & $33(38.4)$ & $29(33.7)$ & $10(11.6)$ & $3.34 \pm 1.05$ & \multirow{2}{*}{$<0.001^{*}$} \\
\hline - 2 points or less (mild) & 90 & $0(0.0)$ & $0(0.0)$ & $3(3.3)$ & $18(20.0)$ & $35(38.9)$ & $34(37.8)$ & $4.11 \pm 0.84$ & \\
\hline 6. 3 points or less (mild) in CGI-S & 88 & $0(0.0)$ & $0(0.0)$ & $5(5.7)$ & $32(36.4)$ & $39(44.3)$ & $12(13.6)$ & $3.66 \pm 0.79$ & - \\
\hline
\end{tabular}

Data are presented as N (\%) and mean \pm standard deviation. * p values were derived from Mann-Whitney's U test. PANSS: positive and negative syndrome of scale, CGI-S: clinical global impression-severity, SANS: Scale for the Assessment of Negative Symptoms 
Supplementary Table 4. Frequency distribution of the ranked choice questions for remission evaluation responded to by psychiatrists

\begin{tabular}{cccccc}
\hline Items for considering psychiatric & \multicolumn{5}{c}{ Rank, N (\%) } \\
\cline { 2 - 5 } symptoms in PANSS & 1st choice & 2nd choice & 3rd choice & 4th choice & \multirow{2}{*}{ Weighted average* } \\
\hline All 7 PANSS positive items & $45(53.6)$ & $14(16.9)$ & $22(26.5)$ & $7(8.6)$ & 3.10 \\
5 items (P1, P2, P3, P5, P6) & $4(4.8)$ & $40(48.2)$ & $23(27.7)$ & $15(18.5)$ & 2.40 \\
4 items (P1, P2, P3, P6) & $10(11.9)$ & $20(24.1)$ & $35(42.2)$ & $17(21.0)$ & 2.28 \\
3 items (P1, P2, P3) & $25(29.8)$ & $9(10.8)$ & $3(3.6)$ & $42(51.9)$ & 2.22 \\
\hline
\end{tabular}

*each rank 1st, 2nd, 3rd, 4th priority set to $4,3,2,1$ points. NR: no response 
Supplementary Table 5. Frequency distribution of questionnaire on relapse

\begin{tabular}{|c|c|c|c|c|c|c|c|c|c|}
\hline \multirow{2}{*}{ Items } & \multirow{2}{*}{$\mathrm{N}$} & \multicolumn{6}{|c|}{ Likert scale, frequency (\%) } & \multirow{2}{*}{ Mean $\pm S D$} & \multirow{2}{*}{ p-value } \\
\hline & & 0 & 1 & 2 & 3 & 4 & 5 & & \\
\hline $\begin{array}{l}\text { 1. Hospitalization due to aggravation of psychiatric } \\
\text { symptoms }\end{array}$ & 89 & $0(0.0)$ & $0(0.0)$ & $3(3.4)$ & $9(10.1)$ & $15(16.9)$ & $62(69.7)$ & $4.53 \pm 0.81$ & - \\
\hline \multicolumn{10}{|l|}{ 2. Increase of total PANSS score } \\
\hline$\cdot \geq 25 \%$ & 90 & $1(1.1)$ & $1(1.1)$ & $1(1.1)$ & $12(13.3)$ & $49(54.4)$ & $26(28.9)$ & $4.06 \pm 0.87$ & \multirow{2}{*}{$0.001^{*}$} \\
\hline$\cdot \geq 20 \%$ & 88 & $1(1.1)$ & $1(1.1)$ & $3(3.4)$ & $35(39.8)$ & $31(35.2)$ & $17(19.3)$ & $3.65 \pm 0.95$ & \\
\hline 4. Increasing of medication dosage ( $\geq 25 \%)$ & 90 & $0(0.0)$ & $7(7.8)$ & $18(20.0)$ & $33(36.7)$ & $26(28.9)$ & $6(6.7)$ & $3.07 \pm 1.04$ & - \\
\hline 5. Severe suicidal attempt or suicide & 91 & $0(0.0)$ & $3(3.3)$ & $3(3.3)$ & $13(14.3)$ & $26(28.6)$ & $46(50.5)$ & $4.20 \pm 1.02$ & - \\
\hline 6. Intentional self-injury & 91 & $0(0.0)$ & $2(2.2)$ & $5(5.5)$ & $15(16.5)$ & $38(41.8)$ & $31(34.1)$ & $4.00 \pm 0.97$ & - \\
\hline $\begin{array}{l}\text { 7. Damage to other people or property by violent } \\
\text { behaviors }\end{array}$ & 91 & $0(0.0)$ & $0(0.0)$ & $1(1.1)$ & $18(19.8)$ & $40(44.0)$ & $32(35.2)$ & $4.13 \pm 0.76$ & - \\
\hline \multicolumn{10}{|l|}{$\begin{array}{l}\text { 8. Changes of scores in P7 (hostility) or G8 } \\
\text { (uncooperativeness) for } 2 \text { consecutive days }\end{array}$} \\
\hline$\bullet \geq 6$ points (severe) & 89 & $0(0.0)$ & $0(0.0)$ & $2(2.2)$ & $15(16.9)$ & $37(41.6)$ & $35(39.3)$ & $4.18 \pm 0.79$ & \multirow{2}{*}{$0.005^{*}$} \\
\hline$\cdot \geq 5$ points (moderate severe) & 90 & $0(0.0)$ & $0(0.0)$ & $1(1.1)$ & $30(33.3)$ & $39(43.3)$ & $20(22.2)$ & $3.87 \pm 0.77$ & \\
\hline $\begin{array}{l}\text { 9. } \geq 6 \text { points (much worse) or } 7 \text { points (very much } \\
\text { worse) in CGI-I }\end{array}$ & 90 & $0(0.0)$ & $0(0.0)$ & $1(1.1)$ & $3(3.3)$ & $27(30.0)$ & $59(65.6)$ & $4.60 \pm 0.61$ & - \\
\hline 10. More by increases by 2 points or more in CGI-S & 90 & $0(0.0)$ & $0(0.0)$ & $1(1.1)$ & $20(22.2)$ & $47(52.2)$ & $22(24.4)$ & $4.00 \pm 0.72$ & - \\
\hline $\begin{array}{l}\text { 11. Increase in the level (frequency of visiting) of } \\
\text { psychiatric practice }\end{array}$ & 90 & $0(0.0)$ & $6(6.7)$ & $17(18.9)$ & $39(43.3)$ & $22(24.4)$ & $6(6.7)$ & $3.06 \pm 0.99$ & - \\
\hline
\end{tabular}

Data are presented as N (\%) and mean \pm standard deviation. ${ }^{*} \mathrm{p}$ values were derived from Mann-Whitney's U test. PANSS: positive and negative syndrome of scale, CGI-S: clinical global impression-severity, CGI-I: clinical global impression-improvement 
Supplementary Table 6. Frequency distribution of the ranked choice questions for relapse evaluation responded to by psychiatrists

\begin{tabular}{lcccc}
\hline Items for considering psychiatric & \multicolumn{3}{c}{ Rank, N (\%) } & \multirow{2}{*}{ Weighted average* } \\
\cline { 2 - 4 } symptoms in PANSS & 1st choice & 2nd choice & 3rd choice & 2.02 \\
Any of all 7 PANSS positive items & $38(43.2)$ & $16(18.8)$ & $36(42.9)$ & 1.92 \\
Any of 5 items (P1, P2, P3, P5, P6) & $11(12.5)$ & $55(64.7)$ & $18(21.4)$ & 2.11 \\
Any of 4 items (P1, P2, P3, P6) & $39(44.3)$ & $14(16.5)$ & $30(35.7)$ & \\
\hline
\end{tabular}

*each rank 1st, 2nd, 3rd priority set to 3, 2, 1 point 
Supplementary Table 7. Frequency distribution of questionnaire on recovery

\begin{tabular}{lcccccccc}
\hline \multirow{2}{*}{\multicolumn{1}{c}{ Items }} & $\mathrm{N}$ & \multicolumn{7}{c}{ Likert scale, frequency (\%) } \\
\cline { 3 - 9 } & & 0 & 1 & 2 & 3 & 4 & 5 & Mean \pm SD \\
\hline 1. Dividing full and partial recovery & 90 & $2(2.2)$ & $4(4.4)$ & $5(5.6)$ & $10(11.1)$ & $34(37.8)$ & $35(38.9)$ & $3.94 \pm 1.22$ \\
6. $\leq 36$ in PANSS total score & 86 & $1(1.2)$ & $3(3.5)$ & $11(12.8)$ & $25(29.1)$ & $40(46.5)$ & $6(7.0)$ & $3.37 \pm 0.99$ \\
\hline
\end{tabular}

PANSS: positive and negative syndrome of scale 
Supplementary Table 8. Frequency distribution of the choice questions for 'Recovery' evaluation responded by psychiatrists

\begin{tabular}{|c|c|c|c|}
\hline \multirow{2}{*}{ Items } & \multicolumn{2}{|c|}{ Definition } & \multirow{2}{*}{ p value* } \\
\hline & Partial recovery & Full recovery & \\
\hline Criteria for SOCIAL FUNCTIONING & & & $<0.001$ \\
\hline - He or she has an personal relationship that is age-appropriate. & $40(46.0)$ & $78(85.7)$ & \\
\hline - He or she has a social contact with friends or a lover more than once a week. & $2(2.3)$ & $0(0.0)$ & \\
\hline - He or she meets friends, seniors, or relatives more than once a month. & $2(2.3)$ & $3(3.3)$ & \\
\hline $\begin{array}{l}\text { - He or she meets friends, seniors, or relatives more than once a month, or he or she makes phone } \\
\text { calls with other people at least twice a month (other than text message and chat application). }\end{array}$ & $1(1.1)$ & $0(0.0)$ & \\
\hline - He or she meets friends, seniors, or relatives more than twice a month. & $7(8.0)$ & $3(3.3)$ & \\
\hline $\begin{array}{l}\text { - He or she meets friends, seniors, or relatives more than twice a month, or he or she makes phone } \\
\text { calls with other people at least twice a month (other than text message and chat application). }\end{array}$ & $35(40.2)$ & $0(0.0)$ & \\
\hline - He or she tries to meet friends, seniors or relatives more than four times a month. & $0(0.0)$ & $7(7.7)$ & \\
\hline Criteria for OCCUPATIONAL FUNCTIONING & & & $<0.001$ \\
\hline - He or she has appropriate occupational or academic functions/housewife is doing proper housework & $22(25.6)$ & $61(68.5)$ & \\
\hline $\begin{array}{l}\text { - When the duration of employment or employment preparation is at least } 1 / 3 \text { of the period of } \\
\text { maintaining remission state/When the housewife was able to perform housework to some extent }\end{array}$ & $9(10.5)$ & $0(0.0)$ & \\
\hline $\begin{array}{l}\text { - When the duration of employment or employment preparation is at least half period of maintaining } \\
\text { remission state/When the housewife was able to perform housework to some extent }\end{array}$ & $15(17.4)$ & $19(21.3)$ & \\
\hline $\begin{array}{l}\text { - When the duration of employment or employment preparation is whole period of maintaining } \\
\text { remission state/When the housewife was able to perform housework to some extent }\end{array}$ & $40(46.5)$ & $0(0.0)$ & \\
\hline $\begin{array}{l}\text { - When the duration of employment or employment preparation is whole period of maintaining } \\
\text { remission state/When the housewife was able to do faithfully housework }\end{array}$ & $0(0.0)$ & $9(10.1)$ & \\
\hline Symptoms of psychopathology (using PANSS for criteria of remission) & & & $<0.001$ \\
\hline - $\leq 3$ points (mild) & $66(77.6)$ & $3(3.8)$ & \\
\hline$\cdot \leq 2$ points (minimal) & $12(14.1)$ & $8(10.0)$ & \\
\hline - absent & $7(8.2)$ & $69(86.3)$ & \\
\hline Using SANS for criteria of remission & & & $<0.001$ \\
\hline - $\leq 3$ points (mild) & $58(69.0)$ & $5(6.0)$ & \\
\hline$\cdot \leq 2$ points (minimal) & $21(25.0)$ & $18(21.7)$ & \\
\hline - absent & $5(6.0)$ & $60(72.3)$ & \\
\hline Medication & & & $<0.001$ \\
\hline - Chlorpromazine equivalent to $300 \mathrm{mg}$ (risperidone $3 \mathrm{mg}$ ) or less daily & $40(48.8)$ & $7(8.6)$ & \\
\hline - Chlorpromazine equivalent to $200 \mathrm{mg}$ (risperidone $2 \mathrm{mg}$ ) or less daily & $33(40.2)$ & $25(30.9)$ & \\
\hline - No medication & $9(11.0)$ & $49(60.5)$ & \\
\hline CGI-S & & & $<0.001$ \\
\hline$\cdot \leq 3$ points (mild) & $59(70.2)$ & $2(2.4)$ & \\
\hline - $\leq 2$ points (very mild or minor) & $18(21.4)$ & $7(8.4)$ & \\
\hline - $\leq 1$ points (not ill) & $7(8.3)$ & $74(89.2)$ & \\
\hline
\end{tabular}

Data are presented as $\mathrm{N}(\%)$ and mean \pm standard deviation. ${ }^{*}$ p values were derived from Fisher's exact test 
Supplementary Table 9. Appropriate duration for each definition

\begin{tabular}{lccccccc}
\hline \multicolumn{1}{c}{ Items } & $\mathrm{N}$ & \multicolumn{3}{c}{ Duration } \\
\hline The appropriate time For deciding treatment response after starting treatment & 90 & 1 week & 2 weeks & 3 weeks & 4 weeks & 5 weeks & 6 weeks \\
& & $1(1.1)$ & $14(15.6)$ & $8(8.9)$ & $48(53.3)$ & $0(0.0)$ & $19(21.1)$ \\
The duration of stable state for defining remission & 91 & 1 week & $1 \mathrm{Mo}$ & $2 \mathrm{Mo}$ & $3 \mathrm{Mo}$ & $6 \mathrm{Mo}$ & $12 \mathrm{Mo}$ \\
& & $0(0.0)$ & $1(1.1)$ & $3(3.3)$ & $6(6.6)$ & $30(33.0)$ & $51(56.0)$
\end{tabular}

